\title{
Effect of ventilation on systemic blood flow evaluated by echodopplercardiography
}

M. Rigatto and

A.F.F. Pinotti
Departamento de Medicina Interna, Hospital de Clínicas, Universidade Federal do Rio Grande do Sul, 90035-003 Porto Alegre, RS, Brasil

\author{
Correspondence \\ M. Rigatto \\ Caixa Postal 5051 \\ 90041-970 Porto Alegre, RS \\ Brasil \\ Presented at the XI Annual Meeting \\ of the Federação de Sociedades de \\ Biologia Experimental, Caxambu, \\ MG, Brasil, August 21-24, 1996. \\ Research supported by $\mathrm{CNPq}$ \\ (No. 305361/76-CL) and FAPERGS \\ (No. 93.0319.6).
}

Received April 19, 1996 Accepted March 7, 1997
The objective of the present study was to analyze the effect of varying rates of breathing on systemic blood flow as measured by echodopplercardiography. An increase in systemic blood flow (Q) by ventilation has been suggested or documented by different methods for measuring cardiac output (110). The echodopplercardiographic method to measure $\mathrm{Q}$ has not yet been employed. This method has interesting qualifications for this purpose: it does not interfere with breathing or the ventilatory airways, as the Fick principle and the foreign gas methods do, it is not limited in time by blood pulmonary recirculation, as the foreign gas methods are, it is not an invasive method, as the Fick and the dilution methods are, it is more reliable than the transthoracic electrical impedance method, and it can be utilized during apnea, when the Fick and the foreign gas methods cannot.

Five normal resting adult males, ranging in age from 24 to 37 years (mean, 31.8), 167 to $185 \mathrm{~cm}$ in height (mean, 176.8) and 72 to $86 \mathrm{~kg}$ in weight (mean, 78.6), were studied in a recumbent posture at eupnea, tachypnea and apnea. Tidal volume was kept constant from eupnea to tachypnea. Apnea was held for $30 \mathrm{~s}$ at functional residual levels with an open glottis. Ventilation was monitored with a respiration monitoring system (No. 1200162-0001, Echo Ultrasound, Reedsville, PA). Systemic blood flow was measured by bidimensional echodopplercardiographic 
(HP-Sonos 1000, Hewlett Packard, Andover, MS) determination of the diameters of the left ventricle outflow, allowing the calculation of the cross-sectional area of the aortic annulus, and the beat-by-beat integration of the blood flow velocity profile at this level.

Table 1 - Measurement of ventilatory and circulatory parameters by echodopplercardiography.

Data are reported as means \pm SEM for 5 normal young adult male volunteers. RF, Respiratory frequency; HR, heart rate; SV, stroke volume; $\mathrm{Q}$, systemic blood flow.

\begin{tabular}{lcccc}
\hline Ventilation state & $\mathrm{RF}(\mathrm{mpm})$ & $\mathrm{HR}(\mathrm{bpm})$ & $\mathrm{SV}(\mathrm{ml})$ & $\mathrm{Q}(\mathrm{l} / \mathrm{min})$ \\
\hline Apnea & 0 & $61.8 \pm 4.5$ & $76.1 \pm 1.3$ & $4.64 \pm 0.17$ \\
Eupnea & $13.4 \pm 1.6$ & $64.0 \pm 4.9$ & $81.5 \pm 4.7$ & $5.15 \pm 0.15$ \\
Tachypnea & $24.0 \pm 3.6$ & $70.6 \pm 5.3$ & $81.6 \pm 4.3$ & $5.67 \pm 0.14$
\end{tabular}

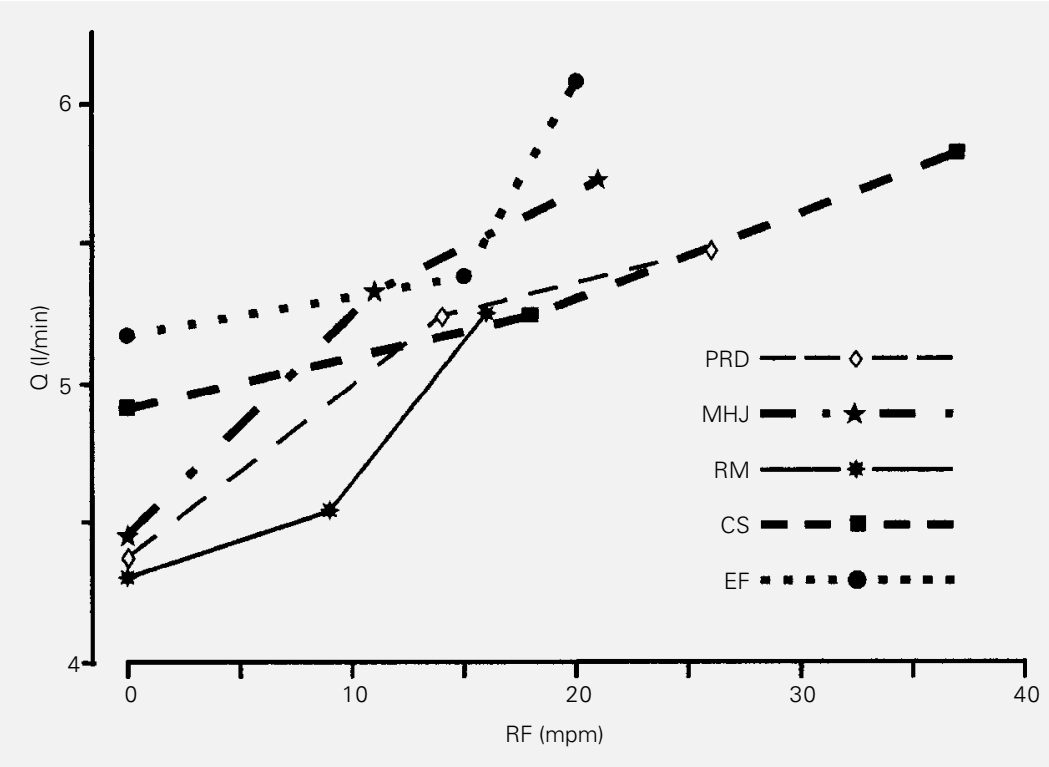

Figure 1 - Changes of systemic blood flow (Q) with respiratory frequency (RF) at apnea, eupnea and tachypnea measured by echodopplercardiography. Each line drawing corresponds to one subject.
The multiplication of the aortic cross-sectional area by the integrated flow led to the beat-by-beat ventricular stroke volume. The mean stroke volume of 10 successive heart beats was then multiplied by the mean heart rate during this period to produce cardiac output (systemic blood flow) (11). An electrocardiographic tracing was recorded during each run. A 3-min interval was allowed between runs.

Considering the non-invasive, routine diagnostic techniques used in the study, no restriction was raised to it by the Hospital Ethics Committee. Oral informed consent was obtained from each subject.

For the whole series, the respiratory frequency (RF) was $13.4 \pm 1.6 \mathrm{mpm}$ (mean \pm SEM) at eupnea and $24.0 \pm 3.6 \mathrm{mpm}$ at tachypnea. Heart rate (HR) was $61.8 \pm 4.5$ bpm at apnea, $64.0 \pm 4.9$ at eupnea and 70.6 \pm 5.3 at tachypnea. Stroke volume was 76.1 $\pm 1.3 \mathrm{ml}$ at apnea, $81.5 \pm 4.7$ at eupnea and $81.6 \pm 4.3$ at tachypnea. Systemic blood flow (cardiac output; Q) was $4.64 \pm 0.17 \mathrm{l} / \mathrm{min}$ at apnea, $5.15 \pm 0.15$ at eupnea and $5.67 \pm 0.14$ at tachypnea (Table 1).

Figure 1 shows a positive correlation between systemic blood flow and respiratory frequency. When RF was reduced from eupnea to apnea, Q was reduced by $10 \%$. By doubling RF from eupnea to tachypnea, Q was increased by a similar magnitude. The positive correlation between ventilation and systemic blood flow, as shown in the present study by echodopplercardiography, is in agreement with previous studies (5-10) in which other methods for the determination of cardiac output were used, including the only other study which considered changes from eupnea to apnea (9). 


\section{References}

1. Armitage GH \& Arnott WM (1949). Effect of voluntary hyperpnea on pulmonary blood flow. Journal of Physiology, 109: 64-69.

2. Baxter IGM \& Pearce JM (1951). Simultaneous measurements of pulmonary arterial flow and pressure using condenser manometers. Journal of Physiology, 115: 410-429.

3. Bevegård S, Jonsson B, Karlöf I \& Aström $H$ (1967). Circulatory effects of increased ventilation at rest in recumbent and headup tilted position. Acta Medica Scandinavica, 472 (Suppl): 59-67.

4. Jager SDE (1879). Über den Blutstrom in den Lungen. Archive für die Gesamte Physiologie, 20: 426-508.
5. Krogh A \& Lindhard J (1912). Measurements of the blood flow through the lungs of man. Skandinavian Archives of Physiology, 27: 100-125.

6. Macklin CC (1945). Length and width changes in the pulmonary arterial system of rabbits in passing from the stage of expiration to that of collapse as revealed by roentgenography. Diseases of the Chest, 11: 590-595.

7. Rigatto $M$, Turino $G M$ \& Fishman $A P$ (1961). Determination of the pulmonary capillary blood flow in man. Circulation Research, 9: 945-962.

8. Rigatto M (1967). Mass spectrometry in the study of pulmonary circulation. Bulletin de Physio-Pathologie Respiratoire, 3: 473-486.
9. Rigatto M, Fuller H \& Inman M (1993). Apnea, tachypnea and systemic blood flow. Arquivos Brasileiros de Cardiologia, 61 (Suppl II): 2: 39 (Abstract).

10. Thompson Jr HK, Berry JN \& Mclntosch HD (1962). Circulatory responses to hyperventilation and exercise in normal subjects. American Heart Journal, 63: 106114.

11. Lewis JF, Lawrence CK, Nelson JG, Limacher MC \& Quinones MA (1984). Pulsed Doppler echocardiographic determination of stroke volume and cardiac output: clinical validation of two new methods using the apical window. Circulation, 70: 425-431. 